\title{
Psychosocial Determinants of Medication Adherence Among Psychiatric Outpatients
}

\author{
Olutope E. Akinnawo Daniel O. Kumuyi Bede C. Akpunne* \\ Department of Behavioural Studies, Faculty of Social Sciences, Redeemer's University, Osun State, Nigeria
}

\begin{abstract}
Medication adherence refers to compliance by patients in taking their prescribed medications as instructed by their doctors. Lack of treatment adherence has shown to be associated with negative attitude to pharmacotherapy. This study was set out to determine the influence of psychosocial factors on medication adherence among outpatient of Federal Neuro-psychiatric Hospital Yaba, Lagos. The study adopted survey design with a randomized sample of 277 participants selected purposively. The participant responded to Big Five Personality Inventory (BFI), Religiosity Oriented Test (ROT) and Morisky Medication Adherence Scale (MMAS-8). Data was analyzed using descriptive and inferential statistics. The result revealed a $44.8 \%$ and a $55.2 \%$ prevalence of high and low medication adherence respectively. Observed significant independent determinants of medication adherence among the outpatients include personality traits $\left(\mathrm{R}^{2}=.034 p=.000\right)$ and religiosity $\left(\mathrm{R}^{2}=.037 p=.001\right)$. Personality traits and religiosity jointly predicted medication adherence $\left(\mathrm{R}^{2}=.024, p=.000\right)$. Respondents' nature of illness ( $\mathrm{F}$ $(4,273)=8.81, p=.000)$ as well as level of education $(\mathrm{F}(5,271)=5.964, p=.000)$ significantly influenced medication adherence. Findings concluded that personality traits, religiosity, nature of illness and educational level are psycho-social determinants of medication adherence among outpatients. Authors recommend psychoeducation to enlightenment of patients on the importance of adherence to medication.
\end{abstract}

Keywords: Personality traits, religiosity, medication adherence, psychiatric outpatients

DOI: $10.7176 / \mathrm{JHMN} / 69-08$

Publication date: December $31^{\text {st }} 2019$

\section{Introduction}

According to the World Health Organization (2003), adhering to treatment refers to "the degree to which the behaviour of a person corresponds to the instructions agreed with a medical professional in terms of taking medication, following the recommended diet and making changes in lifestyle". Medication adherence behaviour therefore refers to compliance by patients in taking their prescribed medications as instructed by their doctors, as well as continuing to carry out their instruction throughout the duration of medication usage (Cramar, Roy, Burell, Fairchild, Fuldeore, Ollendorf \& Wong 2008). Adherence can also be either intentional or unintentional, including failing to initially fill or refill a prescription, discontinuing a medication before completing the course of therapy, taking more or less of a medication than prescribed and taking a dose at the wrong time. Lack of treatment adherence has shown to be associated with a worse insight, negative attitude or subjective response to pharmacotherapy, substance abuse, shorter duration of underlying illness, inadequate discharge planning or aftercare environment, and poor therapeutic alliance (Perkins, 2002).

Non-adherence to medication is common among patients with in long-term illnesses. Intentional nonadherence is when a patient consciously decides not to follow the recommended treatment regimen. It is referred to as an active process in deciding to not follow the required treatments and is associated with a patient's motivation, their beliefs about their medicines, disease or prognosis (Mukhtar, Weinman, \& Jackson, 2014). In unintentional non-adherence, patients fail to follow their doctor's recommendations without making a conscious decision to do so, resulting from inadvertent forgetting and inability to follow treatment instructions due to lack of understanding or impaired physical abilities (Mukhtar et al, 2014).

According to the Diagnostic and Statistical Manual of Mental Disorders (DSMIV) of the American Psychiatric Association, "Personality traits are enduring patterns of perceiving, relating to and thinking about the environment and about oneself that are exhibited in a wide range of personal and social context". An individual's personality has been found to predict how that person reacts to other people, how he articulates and solves problems and how he is affected by stressful events in his environment. According to (Booth-Kewley \& Vickers, 1994) agreeableness and conscientiousness have been found to have positive effects on health behaviour. In addition, conscientiousness was positively associated with adherence to medication regimens and neuroticism has been found to have a negative effect on health behaviour and poor drug compliance.

Religion has positive effects on both physical and mental health (Koenig, McCoullough, \& Larson, 2001). Interests in the direct and indirect role of religion on health are on the increase (Miller \& Thoresen, 2003). Accordingly some meta-analysis studies reported that Big Five personality traits correlated with religious involvement and some parts of it dimensions such as; agreeableness and conscientiousness have the most reliable correlations with religiousness (Saroglou, 2002; Lodi-Smith \& Roberts, 2007). On the other hand, in contrast some research findings McCullough, Tsang and Brion (2003) found no significant correlation between religious beliefs 
and extraversion. According to Tsang and McCullough (2003) some forms of religiosity correlate significantly with physical and mental health, tolerance, pro-social behaviour and positive interpersonal relationships. However, McCullough, et al., (2003) reported a positive significant correlation between religiousness and openness to experience.

Medication non-adherence is an important barrier to the successful treatment of the mentally ill and is a frequent cause of exacerbations in psychopathology, psychotic relapse and re hospitalization (Ascher-Syanum, et al., 2006). The association between socio-demographic factors, symptoms severity and type of medication has remained controversial, (Lacro et al. 2002). In an effort to ultimately increase adherence, researchers have examined both the static (i.e., fixed) and dynamic (i.e., variable) factors that most strongly affect overall compliance in individuals with mental illness. Studies have explored numerous static variables such as gender (Atwood \& Beck, 1985; Buchanan, 1992), ethnic minority status (Tunnicliffe, Harrison, \& Standen, 1992), age of illness onset (Leclerc, et al., 2013), type of psychotic symptoms (Duncan \& Rogers, 1998), and level of formal education (Barkof, et al., 2011; Leclerc, et al., 2013). Cooper, Carpenter, Katona, Schroll, Wagner, Fialova, and Livingston (2005) reported that married individuals had higher treatment adherence levels which were attributed to perceived support from spouses. Wang et. al. (2002) found higher medication adherence levels in females than males.

The Theory of Reasoned Action (Fishbein, 1967), suggests a patient's knowledge and ability to obtain knowledge influences the development of their beliefs. When faced with self-management tasks, patients weigh many factors, including their beliefs about the necessity or concerns about medicines which ultimately leads to the decision to adhere or not to adhere to the prescribed treatments (Horne \& Weinman, 1999). In an examination of the influence of belief about medicines on adherence, Emilson and colleagues (2011) found a positive relationship between necessity of medication for controlling illness and adherence. Beliefs about medicine has shown to be an important factor that most affects medication adherence in individuals with diabetes (Horne, 1997; Horne \& Weinman, 1999, \& Horne, 2006). A study examining belief about medicines and adherence in patients with type II diabetes carried out by Sweileh, Zyoud, Abu Nab', Deleq and Al-Jabi, (2014) demonstrated that the participants who believed their medicines to be of concern and anxiety were shown to be non-adherent to treatments.

Medication non-compliance is a major risk factor for relapse in mental illness (Marder, 1998; Geddes et al 2003). It is estimated that fewer than $10 \%$ of people with unipolar major depression take the appropriate therapeutic dose of medication, and more than $20 \%$ fail to even fail their first prescription (Keller \& Boland 1998). Furthermore, people often discontinue their medication long before it is advised by their medical practitioner. Adherence to taking antipsychotic medication is particularly problematic, and a wide range of factors (Marland \& Cash 2001; Sweileh, et al, 2014).

In Nigeria, the subject of mental health is often culturally evaded as many people are not usually inclined to discuss it openly (Bakare, 2014). Unlike in western world there is paucity of studies on medication adherence carried out in the developing world. This is not surprising taking into cognizance the ignorance, myth solely based on tradition and superstition, negatively shape the attitude of most people towards the etiology and solutions of most illnesses, especially mental disorders in this part of the world (Chukwujekwu, \& Stanley, 2008). There is a dearth of information on medication adherence among psychiatric patients especially in the area of the psychological and social factors in Nigeria. Hence, this present study explores some extraneous psychosocial factors that influence medication adherence among outpatients of Neuro-psychiatric Hospital Lagos Nigeria. Our focus includes ascertaining if personality traits and religiosity significantly predicts medication adherence, establishing the influence of nature of illness as well as educational background on medication adherence among outpatients of Federal Neuro-psychiatric Hospital (NPH) Yaba, Lagos Nigeria.

\subsection{Research Questions}

In the light of the aforementioned problem gaps, the following research questions will this study:

1. Does personality traits significantly determine medication adherence among outpatients of NPH Yaba Lagos Nigeria?

2. To what degree will religiosity significantly determine medication adherence among the participants?

3. Does nature of illness significantly influence medication adherence among the psychiatric outpatients?

4. Will educational level significantly influence medication adherence among outpatients of Federal Neuropsychiatric Hospital Yaba Lagos Nigeria?

\section{Materials and Methods \\ 2.1 Participants}

The target population was outpatient in Neuro-psychiatric Hospital (NPH), Yaba Lagos, Nigeria. Only outpatients who were above 18 years, who could read and understand English language were purposively selected using a cross sectional approach to participate in this study. Outpatients who were fondly psychotic patients were excluded from the study. Using the sample size determination formula by Araoye (2004) a total of 277 outpatients were 
selected.

\subsection{Measures}

A battery of three instruments was adapted and used as tools for data collection.

Big-Five Inventory (BFI) by John, Donahue, \& Kentle, (1991). The version used is a forty four (44) item scale graded on a five-degree scale from completely disagree $=1$ to completely agree $=5$. Cronbach's Alpha coefficients for the five factors are neuroticism $r=0.78$, extraversion $r=0.61$, conscientiousness $r=0.68$, agreeableness $r=$ 0.74 and openness $r=0.75$. The BFI has been used on Nigerian populations and was found to have similar psychometric properties when compared to western population (Omoluabi 2002, Okhakhume 2015, Ugalahi 2017). In a validation study Umeh (2004) highlighted a comparative report of American and Nigerian population; this is summarized in table 1 .

Table 1 Comparison Table of American and Nigerian BFI Mean and Standard Deviation

\begin{tabular}{|l|l|l|l|l|l|l|l|l|l|l|l|}
\hline & \multicolumn{2}{|l|}{ Openness } & \multicolumn{2}{l|}{ Contentiousness } & \multicolumn{2}{|l|}{ Extraversion } & \multicolumn{2}{|l|}{ Agreeableness } & \multicolumn{2}{l|}{ Neuroticism } \\
\hline & Mean & S.D & Mean & S.D & Mean & S.D & Mean & S.D & Mean & S.D \\
\hline $\begin{array}{l}\text { American } \\
\text { population }\end{array}$ & 3.92 & 0.66 & 3.45 & 0.73 & 3.35 & 0.90 & 3.64 & 0.72 & 3.32 & 0.82 \\
$\begin{array}{l}\text { Nigerian } \\
\text { population }\end{array}$ & 3.64 & 0.59 & 3.73 & 0.71 & 3.01 & 0.70 & 3.98 & 0.81 & 2.80 & 1.82 \\
\hline
\end{tabular}

Comparison table of BFI mean and standard deviation of American and Nigerian population (Umeh, 2004) as cited by Oladimeji (2018).

Religious Orientation Test (ROT) a six-item scale that identifies two types of religious orientations: superficial religious orientation and deep religious orientation. The scale has been found to demonstrate good internal consistency. Idehen (2001) used the ROT on a sample of 160 and found alpha values between 0.76 and 0.80 and an internal consistency Cronbach alpha of 0.80 , with a test retest reliability correlation of 0.75 .

Morisky Medication Adherence Scale (MMAS-8) is an 8-item instrument developed by Morisky et.al (2008) was used to assess medication adherence among patients with different clinical conditions. MMAS- 8 has been validated for use in Nigeria (Abiola, Udofia, \& Zakari, 2013). It has shown good psychometric properties, with Cronbach's alpha of 0.77 and internal consistency reliability of $\alpha=0.75$

\subsection{Data Analyses}

The data was analyzed using SPSS package 23. Descriptive statistics (Simple percentages) and inferential statistics (One way ANOVA, and linear regression) were used for this study.

\section{Results}

\subsection{Demographic Characteristics of Participants.}

Demographic results show that $53.8 \%$ (149) of the respondents were males while $46.2 \%$ (128) were females. The mean $( \pm$ SD) age of the participants is $33.78 \pm 8.56$. Distribution by Religious affiliation revealed that $71.5 \%(198)$ of the respondents were affiliated to Christianity, $19.9 \%$ (55) were affiliated to Islam while $8.7 \%$ (24) are traditional worshippers. Educational level descriptive revealed that 5.8\% (16) were primary education categories, $6.5 \%$ (18) were junior secondary school, $27.8 \%$ (77) were senior secondary school education, $9.0 \%(25)$ were OND, and 42.2\% (117) were HND / BSc degree holders, while 8.3\% (21) were Master's degree /PhD level of educational level. Distribution by Nature of illness revealed that 15.2\% (42) presented with schizophrenia, 20.4\% (56) were bipolar, $18.4 \%$ (51) presented with major depression disorder, and $30.7 \%(85)$ presented with substance abuse while others were $15.5 \%$ (43).

\subsection{Patterns of Medication Adherence}

As presented in the Table 2, out of two hundred seventy-seven 277 respondents in study 125 (44.8\%) reported high medication adherence while $152(55.2 \%)$ reported a low medication adherence.

Table 2: Patterns of medication adherence among outpatients

\begin{tabular}{ccc}
\hline & & $\mathbf{N}=\mathbf{2 2 7}$ \\
\hline Medication Adherence & $\mathbf{N}$ & $\mathbf{\%}$ \\
\hline High & 125 & 44.8 \\
Low & 152 & 55.2 \\
Total & 277 & 100 \\
\hline
\end{tabular}

\subsection{Hypotheses Testing}

Hypothesis One: Personality traits will significantly determine medication adherence among outpatients of Federal Neuro-psychiatric Hospital in Lagos Nigeria.

This hypothesis was tested using multiple regression analysis to determine the composite relationship of the 
independent variables on medication adherence. The result summarized on Table 3 indicated that there was significant joint influence of personality traits on medication adherence, $\left[\mathrm{F}(5,277)=27.87, \mathrm{R}^{2}=.034 ; p=.000\right]$ with the variables accounting for $3.4 \%$ of the variance in medication adherence. Further result show that extraversion $(\beta=.13 ; \mathrm{t}=2.01)$, agreeableness $(\beta=-.27 ; \mathrm{t}=-4.46)$ and conscientiousness $(\beta=-.17 ; \mathrm{t}=-7.09)$, had significant independent beta contributions in predicting medication adherence among the outpatients.

Table 3: Multiple regression analysis of medication adherence by personality traits

\begin{tabular}{|c|c|c|c|c|c|c|c|}
\hline & & & & \multicolumn{4}{|c|}{$\mathrm{N}=277$} \\
\hline Predictors & $\mathbf{B}$ & $\beta$ & $\mathbf{t}$ & sig & $\mathbf{R}^{2}$ & $\mathbf{F}$ & $p$ \\
\hline Extraversion & .048 & .131 & 2.011 & .045 & & & \\
\hline Agreeableness & -.075 & -.278 & -4.459 & .000 & .034 & 27.873 & .000 \\
\hline Conscientiousness & -.120 & -.384 & -7.092 & .000 & & & \\
\hline Neuroticism & -.014 & -.039 & -.571 & .568 & & & \\
\hline Openness to experience & -.032 & -.127 & -1.914 & .057 & & & \\
\hline
\end{tabular}

Hypothesis Two: Religiosity will significantly determine medication adherence among outpatients of Federal Neuro-psychiatric hospital Yaba.

A simple linear regression analysis was carried out to determine the degree to which religiosity independently and significantly predicted medication adherence among the participants. Result indicated that religiosity independently significantly predicted the medication adherence among the sample, $\left(\mathrm{R}^{2}=.037, p=.001\right)$. The analysis summarized in Table 4 suggests that $3.7 \%$ variance of medication adherence is explained by religiosity among the patients.

Table 4: Simple linear regression analysis of medication adherence by religiosity.

\begin{tabular}{cccccccc}
\hline & \multicolumn{1}{c}{} & \multicolumn{3}{c}{$\mathrm{N}=277$} \\
\hline Predictors & $\mathbf{B}$ & $\boldsymbol{\beta}$ & $\mathbf{t}$ & $\mathbf{s i g}$ & $\mathbf{R}^{2}$ & $\mathbf{F}$ & $\boldsymbol{p}$ \\
\hline (Constant) & 14.773 & & 84.032 & .000 & .037 & 10.495 & .001 \\
ROT & -.335 & -.192 & -.3 .240 & .001 & & & \\
\hline
\end{tabular}

Hypothesis Three: Nature of illness will significantly influence medication adherence among outpatients of Federal Neuro-psychiatric hospital Yaba.

A one-way between subjects ANOVA was conducted to compare the medication adherence of the outpatients of Federal Neuro-psychiatric hospital Lagos Nigeria based on nature of illness categories. Their nature of illness were classified in five groups namely schizophrenia, bipolar, major depression disorder, substance use, and others. The independent variable represented the five different categories, while the dependent variable was medication adherence scores. Table 5 is a summary of means and standard deviations for each of the five identified nature of illness categories.

Table 5 Means and Standard Deviations of nature of illness categories Scores

$\mathrm{N}=227$

\begin{tabular}{lcccc}
\hline Model & N & Mean & Std. Deviation & Std. Error \\
\hline Schizophrenia & 42 & 15.00 & 1.47 & .22606 \\
Bipolar & 56 & 14.00 & 1.48 & .19739 \\
Depression & 51 & 15.04 & 1.66 & .23257 \\
substance use & 85 & 13.92 & 1.32 & .14320 \\
Others & 43 & 13.79 & 1.37 & .20930 \\
Total & 277 & 14.29 & 1.53 & .09210 \\
\hline
\end{tabular}

An alpha level .05 was used for all analyses. Table 6 show the analysis of variance for the medication adherence of the outpatients based on the nature of their illness categories.

Table 6: Analysis of Variance for medication adherence scores

\begin{tabular}{cccccc}
\hline Model & Sum of Squares & Df & Mean Square & F & Sig. \\
\hline Between Groups & 74.961 & 4 & 18.740 & 8.81 & .000 \\
Within Groups & 580.852 & 273 & 2.128 & & \\
Total & 655.813 & 277 & & & \\
\hline
\end{tabular}

There was a significant difference in medication adherence of the respondents based on the nature of their illness at the $p<.05$ level for the five levels $[F(4,273)=8.81, p=.000]$. Post hoc comparisons using the Tukey HSD test indicated that the mean score for schizophrenia category $(\mathrm{M}=15.00, \mathrm{SD}=1.47)$ was significantly different than Bipolar category $(\mathrm{M}=14.00, \mathrm{SD}=1.48)$, substance use category $(\mathrm{M}=13.92, \mathrm{SD}=1.32)$, and others category $(M=13.92, S D=1.37)$. However, major depression disorder category $(M=15.04, S D=1.66)$ did not significantly differ from schizophrenia category. Taken together, these results suggest that nature of illness really do have significant influence on medication adherence. Specifically, our results suggest that among the outpatients using the Yaba Psychiatric Hospital Lagos, schizophrenia and major depression disorder patients adhere less to 
medication than do the bipolar, substance use disorder and other categories.

Hypothesis Four: Educational level will significantly influence medication adherence among outpatients of Federal Neuro-psychiatric hospital Lagos, Nigeria.

A one-way between subjects ANOVA was conducted to compare the medication adherence of the outpatients of Federal Neuro-psychiatric hospital Lagos Nigeria based on educational level categories. Their highest educational background were classified in six groups namely Primary education, Junior Secondary School Certificate (JSSC), Senior Secondary Certificate Education (SSSCE), Ordinary National Diploma (OND), Bachelors /Higher National Diploma (BSc/ HND), Master's degree / PhD. The independent variable represented the six different categories, while the dependent variable was medication adherence scores. Table 7 is a summary of means and standard deviations for each of the six identified educational qualification categories.

Table 7 Means and Standard Deviations of educational qualification categories Scores

$\mathrm{N}=277$

\begin{tabular}{lcccc}
\hline Models & N & Mean & Std. Deviation & Std. Error \\
\hline Primary educ. & 16 & 15.69 & 1.54 & .38426 \\
JSSCE & 18 & 14.94 & 1.98 & .46773 \\
SSSCE & 77 & 14.36 & 1.43 & .16318 \\
OND & 25 & 14.72 & 1.17 & .23466 \\
HND/BSC & 117 & 13.88 & 1.45 & .13362 \\
Masters/PhD & 24 & 14.13 & 1.48 & .30284 \\
Total & 277 & 14.29 & 1.53 & .09210 \\
\hline
\end{tabular}

An alpha level .05 was used for all analyses. Table 8 show the analysis of variance for the medication adherence of the outpatients based on their educational level categories.

Table 8 Analysis of Variance For medication adherence scores

\begin{tabular}{llclcc}
\hline Model & Sum of Squares & Df & Mean Square & F & Sig. \\
\hline Between Groups & 64.279 & 5 & 12.856 & 5.964 & .000 \\
Within Groups & 584.190 & 271 & 2.156 & & \\
Total & 648.469 & 276 & & & \\
\hline
\end{tabular}

There was a significant difference in medication adherence of the respondents based on the educational qualifications at the $p<.05$ level for the six levels $[F(5,271)=5.964, p=.000]$. Post hoc comparisons using the Tukey HSD test indicated that the mean score for primary education category $(\mathrm{M}=15.69, \mathrm{SD}=1.54)$ was significantly different than SSSCE category $(M=14.36, \mathrm{SD}=1.43), \mathrm{HND} / \mathrm{BSc}$ category $(\mathrm{M}=13.88, \mathrm{SD}=1.45)$, and Masters/PhD category $(\mathrm{M}=14.13, \mathrm{SD}=1.48)$. However, JSSCE category $(\mathrm{M}=14.94, \mathrm{SD}=1.98)$ did not significantly differ from OND category $(M=14.72, \mathrm{SD}=1.17)$. Taken together, these results suggest that educational level really do have significant influence on medication adherence. Specifically, our results suggest that among the outpatients using the Yaba Psychiatric Hospital Lagos, primary education level, Junior secondary school education and Ordinary National Diploma educational level holders adhere less to medication than do the $\mathrm{SSSCE}, \mathrm{HND} / \mathrm{BSc}$ and Master's/PhD categories.

\section{Discussions}

The research finding of our first hypothesis implied that each of the dimensions of personality traits interact together in determining level of outpatient medication adherence. This finding supports Booth-Kewley and Vickers, (1994) who reported that the personality traits of agreeableness and conscientiousness have positive effects on health behavior. In addition, Christensen and Smith, (1995) found conscientiousness to be positively associated with adherence to medication regimens.

The result of our second hypothesis revealed that religiosity is a significant independent predictor of medication adherence among outpatients of Federal Neuro-psychiatric Hospital Yaba Lagos. This is in support of Koenig et al. (2012), who affirmed that religious beliefs may predict medication compliance in mental illness to a large extent; he further affirmed that more religious persons seem to be the more likely of such to involve in disease-screening practices and comply better with prescribed medical treatments. Added to that, spiritual needs are common phenomenon among people for instance; religious beliefs influence medical decision making, drugs adherence (Brink, 1993).

Result of our third hypothesis revealed that nature of illness had significant influence on medication adherence. Schizophrenia and major depression disorder outpatients adhere less to medication than do the bipolar, substance use disorder and other categories. Studies show that between a third and half of medicines that are prescribed for long term conditions are not used as recommended (Haynes, McDonald, Garg, \& Montague, 2002). Researchers have established significant relationship between psychiatric symptom severity and treatment adherence (Duncan \& Rogers, 1998; Tsang et al., 2010), such that as the severity of mental illness symptoms increases, medication adherence decreases (Kampman, et al., 2002; Tsang et al., 2010). Among patients with 
Schizophrenia, those with more severe positive and negative symptoms may be less likely to comply with recommended treatment (Macpherson, Jerrom \& Hughes 1997).

Educational level was found to significantly influence medication adherence among the psychiatric outpatients. Participants with primary education level, Junior secondary school education and Ordinary National Diploma educational level holders were observed to adhere less to medication than do the SSSCE, HND/BSc and Master's degree / PhD categories. Patient's level of education had been reported as a risk factor to medication adherence since poor understanding of the medical instructions, recommendations, or steps to follow adequate treatment does not allow successful healthcare completion with the serious and negative impact that this could have in the patient's wellbeing (Villafuerte-Galvez, J., et al, 2015).

\section{Conclusions and Recommendations}

From the analysis and interpretations of our findings the following conclusions can be deduced. First, personality traits are significant predictors of medication adherence among psychiatric outpatients. Secondly, religiosity is a significantly independent predictor of medication adherence among the participants. Finally, significant difference in nature of illness as well as difference in educational level on medication adherence exists among outpatients of Federal Neuro-psychiatric Hospital Yaba Lagos Nigeria. Psycho-education on the importance of adherence to medication should be given to outpatients on each visit to psychiatric hospital.

\section{Consent and Ethical Approval}

The research intention and proposed procedures for carrying the research was subjected to scrutiny by the Internal Research Ethic Committee (IREC) of Redeemer's University, Ede, Osun State Nigeria and approval granted before the study was embarked upon. A letter of approval was equally obtained from the, Research Ethics Committee of the Federal Neuro-psychiatric Hospital Yaba Lagos Nigeria. The approval was taken to the head of the outpatient ward by the researchers. Respondents who were available and willing to be part of the study on each clinic day were used for this study. The respondents were made to sign an informed consent form which was detached from the questionnaire immediately in order to keep their anonymity. The questionnaires were distributed to them and were given a day to respond to it. Participants were further informed that they could withdraw at any time from the study without any penalty. For confidentiality and other ethical considerations, each respondent was made to sign a consent form. The respondents were given adequate information about the research and were by no means coerced to participate. They all choose to participate on their own volition and were also given the opportunity to ask questions after brief education on what the study is all about in other to diffuse any hidden misconception.

\section{Competing Interests}

Authors have declared that no competing interests exist.

\section{References}

Abiola T, Udofia O, Zakari M (2013) Psychometric properties of the 3-item oslo social support scale among clinical students of Bayero University Kano, Nigeria. Malaysian Journal of Psychiatry 22: 32-41.

Araoye, M.O. (2004). Research methodology with statistics for health and social science. Sample size determination. Nathadex publishers; p. 118-21.

Ascher-Svanum H, Faries D.E, Zhu, B, Ernst FR, Swartz MS, Swanson JW.(2006) Medication adherence and long-term functional outcomes in the treatment of schizophrenia in usual care. $J$ Clin Psychiatry. 2006;67(3):453-460

Atwood, N., \& Beck, J.C. (1985). Service and patient predictors of continuation in clinic based treatment. Hospital and Community Psychiatry, 36(8), 865-869

Bakare, B. (2014). Nigeria and the challenge of mental disorder. Daily Independent Nigeria.

Booth-Kewley, S., \& Vickers, R. R. (1994).Associations between major domains of personality and health behavior. Journal of Personality, 62(3), 281-298.

Brink, T.L. (1993). Religiosity: measurement. In Survey of Social Science: Psychology, Frank N. Magill, Ed., 9

Buchanan, A. (1992). A two-year prospective study of treatment compliance in patients with schizophrenia. Psychological Medicine, 22(3), 787-797.

Christensen, A. J., \& Smith, T. W. (1995). Personality and patient adherence: correlates of the five-factor model in renal dialysis. Journal of behavioural medicine, 18(3), 305-313.

Chukwujekwu, D.C. \& Stanley, P.C. (2008). Patterns of Aggression among Psychiatric In-Patients at The Jos University Teaching Hospital. Journal of Medicine in the Tropics, 10, 7-13.

Cooper C., Carpenter I., Katona C., Schroll M., Wagner C., Fialova D., \& Livingston G. (2005) The AdHOC Study of older adults' adherence to medication in 11 countries. The American Journal of Geriatric Psychiatry

Cramar, J.A., Roy, A., Burell, A., Fairchild, C.J., Fuldeore, M.J., Ollendorf, D.A. \& Wong, P.K. (2008) Medication Compliance and Persistence: Terminology and Definitions. Value in Health, 11, 44-47. 
Duncan, J. C., \& Rogers, R. (1998). Medication compliance in patients with chronic schizophrenia: Implications for the community management of mentally disordered offenders. Journal of Forensic Science, 43(6), 11331137

Fishbein, M.A. (1967). Attitude and the prediction of behaviour. In M. A. Fishbein (Ed.), Readings in attitude theory and measurement, New York: Wiley, pp. 477-492

Geddes, J. R., Carney, S. M., Davies, C., Furukawa, T. A., Kupfer, D. J., Frank, E., \& Goodwin, G. M. (2003). Relapse prevention with antidepressant treatment in depressive disorders: a systematic review.

Lancet, 361 (9358), 653-661

Haynes, R.B., McDonald, H., Garg, A.X. \& Montague, P. (2002) Interventions for Helping Patients to Follow Prescription for Medications.

Horne, R. (1997). Representation of medication and treatment: advances in theory and measurement. In K.J. Petrie \& J.A Weinman (Eds.) Perceptions of health and illness: current research and applications (pp. 155-88). London: Harwood Academic Press.

Horne, R., \& Weinman, J. (1999). Patient's beliefs about prescribed medicines and their roles in adherence to treatment in chronic physical illness. Journal of psychosomatic research, 47 (6), $555-67$

Idehen, E. (2001). The development and evaluation of a religiosity scale. IFE Psychologia, 9, 58-69

John O.P, Donahue, E.M, \& Kentle R.L. (1991). The big five inventory-versions 4a and 54. Berkeley, CA: University of California, Berkeley, Institute of Personality and Social Research.

Kampman, O., Laippala, P., Vaananen, J., Koivisto, E., Kiviniemi, P., Kilkku, N., et al. (2002). Indicators of medication compliance in first-episode psychosis. Psychiatry Research, 110(1), 39-48.

Keller, M.B, \& Boland R.J.(1998). Implications of failing to achieve successful long-term maintenance treatment of recurrent unipolar major depression. Biol Psychiatry .44:348-360

Koenig, H.G., King, D.E. \& Carson, V.B., (2012). Handbook of religion and health, 2nd ed., Oxford University Press, New York

Koenig, M. E. McCullough, \& Larson, D. B. (2001). Handbook of Religion and Health, Oxford University Press, New York, NY, USA, 1st edition,

Lacro, J.P., Dunn LB., Dolder C.R., Leckband, S.G., \& Jeste DV. (2002). Prevalence of and Risk Factors for Medication No adherence in Patients with Schizophrenia: A Comprehensive Review of Recent Literature. The Journal of Clinical Psychiatry 63: 892-909

Leclerc E, Mansur RB, \& Brietzke (2013). Determinants of adherence to treatment in bipolar disorder: a comprehensive review. J Affect Disord Jul;149(1-3):247-52. doi: 10.1016/j.jad.2013.01.036. Epub 2013 Mar 13.

Lodi-Smith J, Jackson, J.J, Bogg T, Walton K, Wood D, Harms P.D, \& Roberts B.W. (2010) Mechanisms of health: Education and health-related behaviors partially mediate the relationship between conscientiousness and selfreported physical health. Psychology and Health.;25:305-319.

Macpherson, R., Jerrom, B. \& Hughes, A.A (1997). controlled study of education about drug treatment in schizophrenia. British Journal of Psychiatry, 168:709-717.

Marder S.R, (1998). Facilitating compliance with antipsychotic medication. Journal of Clinical Psychiatry, 59 (Suppl 3), 21-25

Marland G.R, \& Cash K. (2001). Long-term illness and patterns of medicine taking: Are people with schizophrenia a unique group? Journal of Psychiatric and Mental Health Nursing, 8(3), 197-204

McCullough, M.E., Tsang, J.A., \&Brion, S. (2003). Personality traits in adolescence as predictors of religiousness in early adulthood: Findings from the Terman Longitudinal Study. Personality and Social Psychology Bulletin, 29(8), 980-991.

Miller, W.R., \& Thoresen, C.E. (2003). Spirituality, religion, and health: An emerging research field. American Psychologist, 58, 24-35.

Morisky DE, Ang A, Krousel-Wood M, Ward HJ. (2008). Predictive validity of a medication adherence measure in an outpatient setting. J Clin Hypertens (Greenwich).10(5):348-54

Mukhtar, O., Weinman, J., \& Jackson, S. (2014). Intentional Non-Adherence to Medications by Older Adults. Drugs \& Aging, 31(3), 149-157.

Okhakhume A. S. (2015). Influence of personality factors and loneliness on mental health among undergraduates of distance learning, University of Ibadan. Contemporary Journal of Applied Psychology.;2(1):122-138.

Oladimeji B.Y. (2018). Psychological assessment techniques in health care. ANOL Publication Ibadan.;185-195

Omoluabi P, F. (2002). Big five inventory manual. Lagos: PPC Nigeria Agency.

Perkins, D.O., (2002) Predictors of noncompliance in patients with schizophrenia. J Clin Psychiatry 63:1121-1128.

Saroglou, V. (2002). Religion and the five factors of personality: Ameta-analytic review. Personality and Individual Differences, 32,15-25.

Sweileh, W. M., Zyoud, S. H., Abu Nab'a, R. J., Deleq, M. I., Enaia, M. I., Nassar, S. M., \& Al-Jabi, S. W. (2014). Influence of patients' disease knowledge and beliefs about medicines on medication adherence: findings from 
a cross-sectional survey among patients with type 2 diabetes mellitus in Palestine. BMC Public Health, 14(1), $1-18$.

Tsang, H. W., Fung, K. M., \& Chung, R. C. (2010).Self-stigma and stages of change as predictors of treatment adherence of individuals with schizophrenia. Psychiatry Research, 180

Tsang, J., \&Brion, S. L. McCullough, M. E., (2003). Personality traits in adolescence as predictors of religiousness on early adulthood: 696 Social Psychological and Personality Science 3(6) Findings from the Terman Longitudinal Study. Personality and Social Psychology Bulletin, 29, 980-991

Tunnicliffe, S., Harrison, G., \& Standen, P.J. (1992). Factors affecting compliance with depot medication treatment in the community. Social Psychiatry and Psychiatric Epidemiology, 27(5), 230-233.

Ugalahi, TO. (2017). Suicidal behaviour among senior secondary school students in Ile-Ife, Nigeria. A dissertation presented to the West African College of Physicians, Faculty of Psychiatry.

Umeh C.S. (2004). The impact of personality characteristics on students' adjustment on campus. Unpublished PhD research monograph, Department of psychology, University of Lagos.

Villafuerte-Galvez, J., Vanga, R., Dennis, M., Hansen, J., Leffler, D. A., Kelly C.P., \& Mukherjee, R. (2015).Factors Governing long-term adherence to a gluten-free diet in adult patients with celiac disease. Alimentary Pharmacology \& Therapeutics, 42(6); 753-760.

Wang PS., Bohn RL., Knight E., Glynn RJ., Mogun H. \& Avorn J. (2002) Noncompliance with antihypertensive medications: the impact of depressive symptoms and psychosocial factors. Journal of General Internal Medicine 17:504-511.

World Health Organization (2003) Adherence to Long-Term Therapies: Evidence for Action. 